\title{
Horner Syndrome
}

National Cancer Institute

\section{Source}

National Cancer Institute. Horner Syndrome. NCI Thesaurus. Code C28155.

Interruption of sympathetic innervation to eye and face. 